PREPARED FOR THE U.S. DEPARTMENT OF ENERGY, UNDER CONTRACT DE-AC02-76CH03073

PPPL-3701

PPPL-3701

UC-70

Flexibility and Robustness Calculations for NCSX

by

N. Pomphrey, R. Hatcher, S.P. Hirshman, S. Hudson, L-P. Ku,

E.A. Lazarus, H. Mynick, D. Monticello, G.H. Neilson, A. Reiman, M.C. Zarnstorff, and the NCSX Team

June 2002

NM|

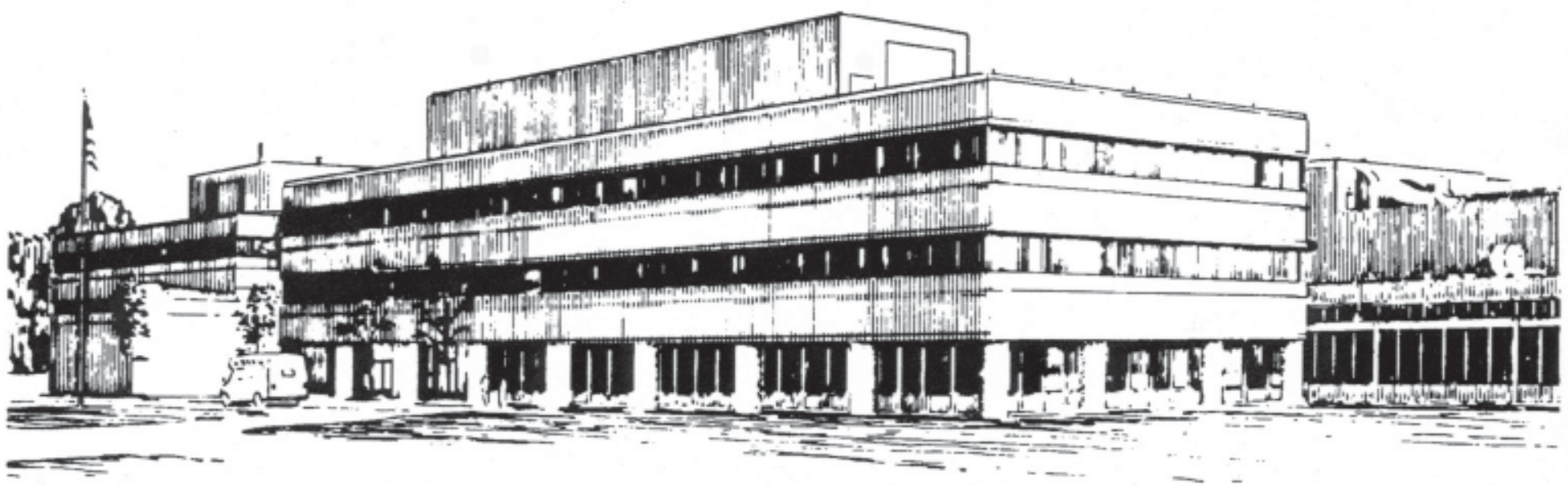

PRINCETON PLASMA PHYSICS LABORATORY PRINCETON UNIVERSITY, PRINCETON, NEW JERSEY 


\section{PPPL Reports Disclaimer}

This report was prepared as an account of work sponsored by an agency of the United States Government. Neither the United States Government nor any agency thereof, nor any of their employees, makes any warranty, express or implied, or assumes any legal liability or responsibility for the accuracy, completeness, or usefulness of any information, apparatus, product, or process disclosed, or represents that its use would not infringe privately owned rights. Reference herein to any specific commercial product, process, or service by trade name, trademark, manufacturer, or otherwise, does not necessarily constitute or imply its endorsement, recommendation, or favoring by the United States Government or any agency thereof. The views and opinions of authors expressed herein do not necessarily state or reflect those of the United States Government or any agency thereof.

\section{Availability}

This report is posted on the U.S. Department of Energy's Princeton Plasma Physics Laboratory Publications and Reports web site in Fiscal Year 2002. The home page for PPPL Reports and Publications is: http://www.pppl.gov/pub_report/

DOE and DOE Contractors can obtain copies of this report from:

U.S. Department of Energy

Office of Scientific and Technical Information

DOE Technical Information Services (DTIS)

P.O. Box 62

Oak Ridge, TN 37831

Telephone: (865) 576-8401

Fax: (865) 576-5728

Email: reports@adonis.osti.gov

This report is available to the general public from:

National Technical Information Service

U.S. Department of Commerce

5285 Port Royal Road

Springfield, VA 22161

Telephone: 1-800-553-6847 or

(703) 605-6000

Fax: (703) 321-8547

Internet: http://www.ntis.gov/ordering.htm 


\title{
FLEXIBILITY AND ROBUSTNESS CALCULATIONS FOR NCSX
}

\author{
N Pomphrey ${ }^{1}$, R Hatcher $^{1}$, S P Hirshman ${ }^{2}$, S Hudson $^{1}$, L-P Ku ${ }^{1}$, E A Lazarus ${ }^{2}$, H Mynick ${ }^{1}$, \\ D Monticello ${ }^{1}$, G H Neilson ${ }^{1}$, A Reiman ${ }^{1}$, M C Zarnstorff ${ }^{1}$ and the NCSX Team \\ ${ }^{1}$ Princeton Plasma Physics Laboratory, Princeton, NJ 08543, USA. \\ ${ }^{2}$ Oak Ridge National Laboratory, Oak Ridge, TN 37831, USA.
}

\section{Introduction}

The National Compact Stellarator Experiment (NCSX) will study the physics of low aspect ratio, high $\beta$, quasi-axisymmetric stellarators. In order to achieve the scientific goals of the NCSX mission ${ }^{1}$, the device must be capable of supporting a wide range of variations in plasma configuration about a reference equilibrium. Numerical experiments are presented which demonstrate this capability.

The NCSX coil-set comprises 18 modular coils, 6 in each of the 3 field periods of the machine. The coils are grouped into 3 independently controlled circuits - one circuit for each distinct coil shape. A novel island-healing algorithm ${ }^{2}$ was incorporated in the coil design methodology to ensure good flux surfaces. A supplementary toroidal field coil system can provide a $0.5 \mathrm{~T} 1 / \mathrm{R}$ field in either direction relative to the modular coil field. This provides the capability to vary the external rotational transform at fixed toroidal field. A system of 6 pairs of axisymmetric poloidal field coils is included for additional flexibility, four of which provide low-order axisymmetric multipole fields, and the remaining two provide an ohmic field.

The primary computational tool for the flexibility studies is STELLOPT, a VMECbased free-boundary optimizer which varies coil currents to generate equilibria with targeted physics properties, such as stability to kink and ballooning modes (conducting wall at infinity) and good quasi-axisymmetry (QA). Essential code modules within STELLOPT include an equilibrium solver $\left(\mathrm{VMEC}^{3}\right)$, stability analysis codes (TERPSICHORE $^{4}$ for kink modes, COBRA $^{5}$ for ballooning modes), and a QA analyser $\left(\mathrm{NEO}^{6}\right.$ which evaluates QA by calculating the effective helical ripple, $\varepsilon_{\mathrm{h}}$ ).

\section{Plasma performance as $\boldsymbol{\beta}$ and $I_{p}$ are varied}

Here STELLOPT is used to calculate coil currents which support stable plasmas with good QA as $I_{p}$ and $\beta$ are varied from their reference values. Profiles of pressure and current are held fixed, equal to a bootstrap-consistent form (see curves labelled $\alpha=0.0$ 
and $\gamma=0.0$ in Fig. 1) appropriate to the $B_{T}=1.7 \mathrm{~T}$ design point (S3) where $I_{p}=174 \mathrm{kA}$, $\beta=4.2 \%$. For a $5 \times 5$ matrix of equally spaced $I_{p}, \beta$ values spanning $I_{p} \in[0,174 k A], \beta \in$ [0, 4\%], STELLOPT successfully produces $\varepsilon_{\mathrm{h}}$-optimized equilibria which are stable to kink and ballooning modes for all $\mathrm{I}_{\mathrm{p}}, \beta$ values, with $\varepsilon_{\mathrm{h}}$ varying within a factor of two of the reference $\left(\varepsilon_{\mathrm{h}}{ }^{\text {ref }}=0.5 \%\right.$ at $\left.\mathrm{s} \sim(\mathrm{r} / \mathrm{a})^{2}=0.5\right)$. In addition, a stable configuration with good quasi-axisymmetry was obtained at $\beta=6 \%$ for $\mathrm{I}_{\mathrm{p}}=174 \mathrm{kA}, \mathrm{B}_{\mathrm{T}}=1.7 \mathrm{~T}$ and reference profiles of current and pressure. (No attempt has yet been made to find the $\beta$-limit for optimized profiles). Modular coil currents vary by less than $\pm 10 \%$ over the $\mathrm{I}_{\mathrm{p}}-\beta$ plane and the auxiliary TF field variation is less than $\pm 0.10 \mathrm{~T}$. Using reference profiles, we conclude there is a substantial region of stability with good QA in the $\mathrm{I}_{\mathrm{p}}-\beta$ plane. For these calculations STELLOPT was run in a mode which provides a cost function penalty for instability but no reward for stability margin. Therefore each equilibrium produced in the $I_{p}, \beta$ scan is marginally stable (as was verified by freezing the coil currents, increasing $\beta$, and noting the appearance of instability). Configurations with a wide range of $\beta$-limits can be easily generated by an appropriate choice of the coil currents.

\section{Plasma performance as profiles are varied}

We now examine plasma performance when plasma profiles are varied about reference forms at fixed $I_{p}$ and $B_{T}$. A 1-parameter sequence of J.B profiles, labelled by parameter $\alpha \in[0,1]$, describing the effect of peaking the current profile in the core of the plasma is shown in Fig. 1a. Using the reference $\mathrm{p}(\mathrm{s})$ and $\mathrm{I}_{\mathrm{p}}=174 \mathrm{kA}, \mathrm{B}_{\mathrm{T}}=1.7 \mathrm{~T}$, STELLOPT finds stable configurations with $\beta \geq 3.0 \%$ for $0 \leq \alpha \leq 0.5$, with $\varepsilon_{\mathrm{h}} \leq 0.5 \%$ at $\mathrm{s}$ $=0.5$. Current profiles with finite edge current have also been examined. At $\beta=5.0 \%$ we find stability is maintained as J.B ${ }^{\text {edge }} / \mathrm{J} . \mathrm{B}^{\max }$ is raised to $50 \%$ ! (dashed curve in Fig. 1a). The stability of stellarators to edge currents ${ }^{7}$ is in contrast with tokamak behavior and leads to the interesting possibility that H-mode profiles may be beneficial to NCSX.

STELLOPT was run for a sequence of pressure profiles (see Fig. 1b) where the peakedness in the core region, parameterized by $\gamma \in[0,1]$, was varied. Fixing $\beta$ at $3.0 \%$ and using the reference J.B current profile, the stable range of $p(s)$ is $0 \leq \gamma \leq 0.8$. For this range of profiles, $\varepsilon_{\mathrm{h}} \leq 0.4 \%$ at $\mathrm{r} / \mathrm{a}=0.5$. The $\gamma=1.0$ configuration is stable at $\beta=2.5 \%$. Finite edge pressure gradients were also studied. Using the pedestal profile shown in Fig. $2 \mathrm{~b}$, a stable configuration at $\beta=3.0 \%$, with $\varepsilon_{\mathrm{h}}=0.56 \%$ was found. 

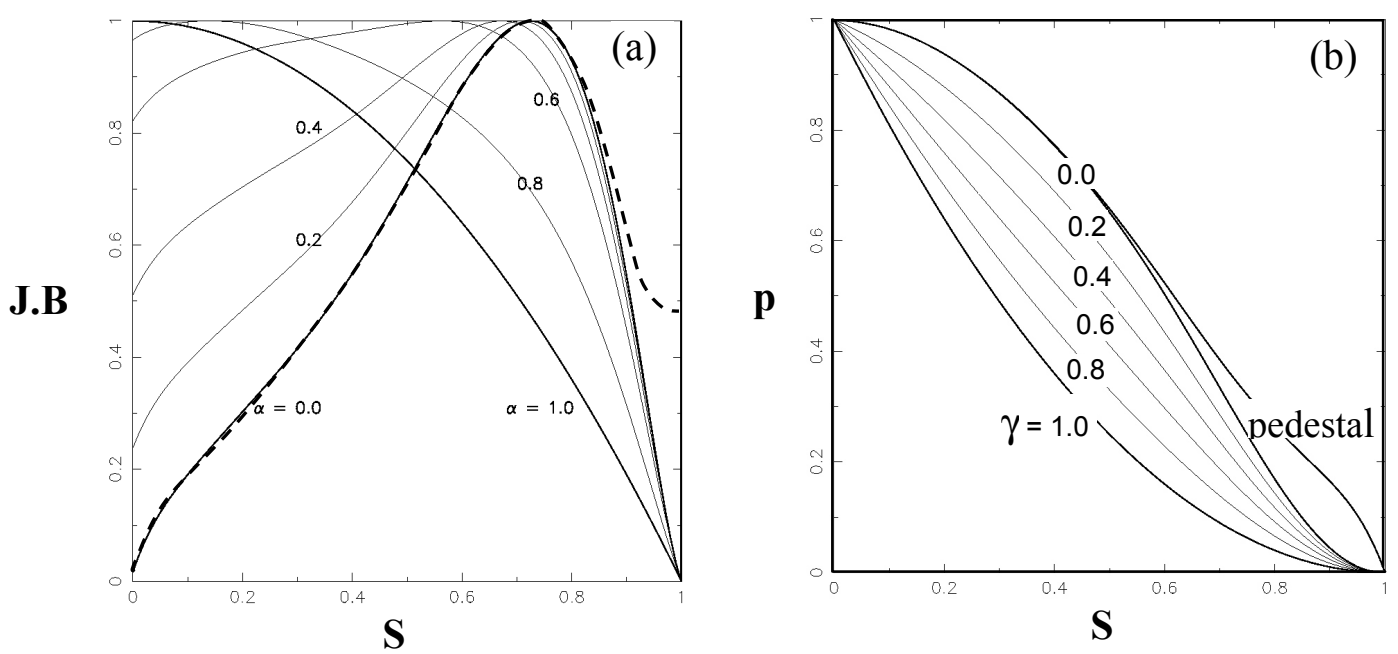

Figure 1: J.B(s) and $p(s)$ profiles used in flexibility studies. $S \sim(r / a)^{2}$ is normalized toroidal flux.

\section{Control of Quasiaxisymmetry}

The ability to generate configurations with good quasi-axisymmetry is an essential requirement of the NCSX design. For a systematic exploration of the role of QA in improving the transport properties of stellarator plasmas, it is necessary to have the ability to control the degree of QA-ness. In this Section we demonstrate this ability, by varying NCSX modular coil currents to induce plasma shape changes that degrade/enhance the QA-ness (measured by the magnitude of the ripple amplitude, $\varepsilon_{\mathrm{h}}$ ) while maintaining plasma stability to kink and ballooning modes. This ability is shown in Fig.2 which shows an overlay of plasma boundaries for three configurations, each with $I_{p}=87.5 \mathrm{kA}, \beta=$ $2.0 \%$, each with the same (reference) profiles of plasma current and pressure, but each exhibiting quite different degrees of quasi-axisymmetry. The modular coil currents vary by approximately $20 \%$ as the QA varies by a factor of ten in this example.
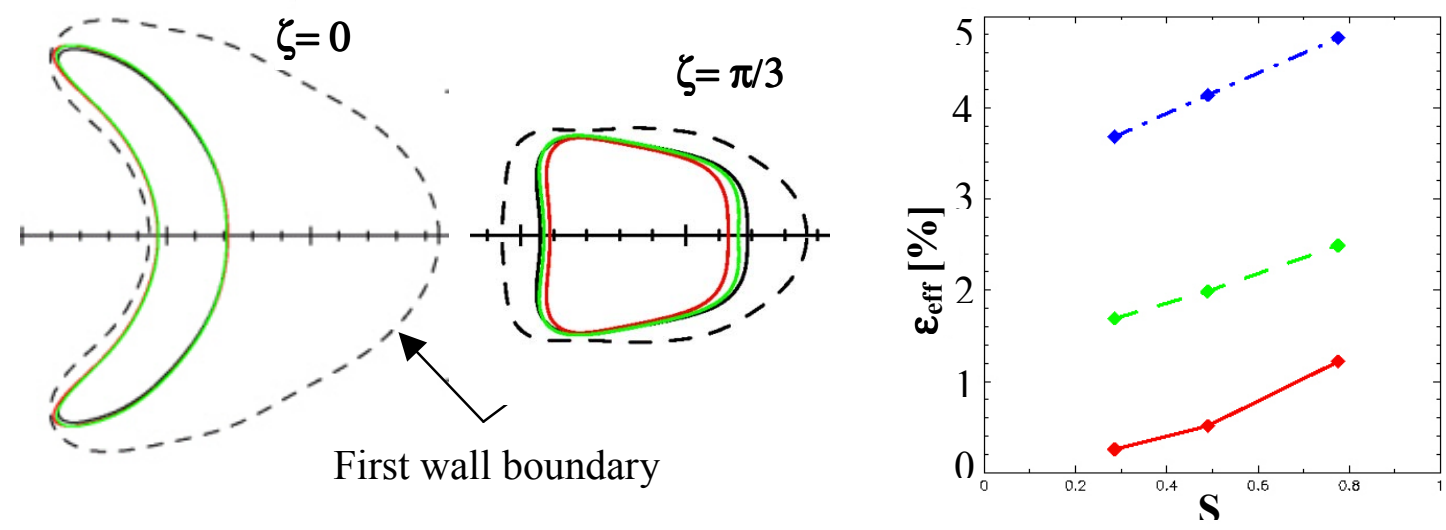

Figure 2: Boundary shapes generated by different modular coil currents for 3 stable onfigurations with $\varepsilon_{\text {eff }}(s=0.5)$ differing by a factor of 10. 


\section{Control of iota profile}

The ability to change the external transform provides a useful control feature in NCSX. Control of $\mathrm{t}(\mathrm{s})$ can be used to test the importance of avoiding low-order rational surfaces in the plasma region; evaluating the role of shear on neoclassical tearing modes; is useful for mapping stability boundaries; and will be useful for establishing controlled conditions for transport experiments. Using reference profiles of pressure and current and fixed reference $S 3$ values of $\beta, I_{p}$ and $B_{T}$ (for which the axis and edge values of iota are $\mathfrak{l}(0)=0.40, \mathfrak{l}(1)=0.65)$ substantial changes $\Delta \mathrm{l}(\mathrm{s}) \in[-0.2,+0.1]$ at constant shear can be accommodated while keeping the shear constant. Similarly, the shear, measured by $\int=$ $\left(l_{\max }-\mathfrak{l}(0)\right)$ can be changed in the range $0.23 \rightarrow 0.53$. Figure $3 \mathrm{a}, \mathrm{b}$ shows $\mathrm{t}(\mathrm{s})$ profiles for the constant shear and variable shear scans at constant $\beta, \mathrm{I}_{\mathrm{p}}$ and $\mathrm{B}_{\mathrm{T}}$. In conjuction with the variation in iota profiles obtained by varying $I_{p}$ and $\beta$ at constant $B_{T}$, shown in Fig $3 c$, the range of iota profiles accessible to NCSX is very broad.
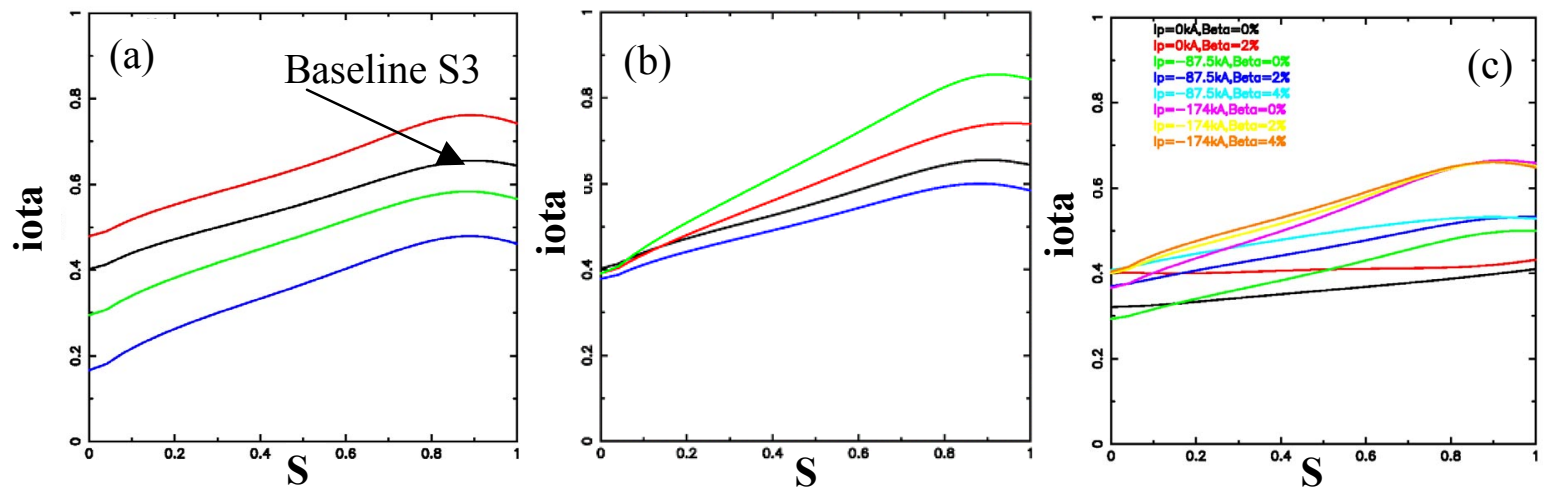

Figure 3a,b: Range of iota variation achieved by varying coil currents at fixed $I_{p}$ and $B_{T}$. 3c: Range of iota profiles obtained by varying $I_{p}$ and $\beta$ at constant $B_{T}$.

\section{Acknowledgements}

Research supported by the U.S. Department of Energy under contract DE-AC02-6CH03073,

\section{References}

[1] M.C. Zarnstorff et al., Plasma Phys. Control. Fusion 43, A237 (2001)

[2] S. R. Hudson, A. Reiman, D. Strickler, A. Brooks, D.A. Monticello and S.P.Hirshman, Plasma Phys. Control Fusion 44, (2002)

[3] S.P. Hirshman, W.I. Van Rij and P. Merkel, Comput. Phys. Commun. 43, 143(1986)

[4] D.V. Anderson, W. A. Cooper, R. Gruber, S. Merazzi and U. Schwenn, Supercomputer 8, 32 (1991)

[5] R. Sanchez, S.P. Hirshman, J.C. Whitson and A.S. Ware, J. Comput. Physics 161, 576 (2000)

[6] V.V. Nemov, S.V. Kasilov, W. Kernbichler and M.F. Heyn, Physics of Plasmas 6, 4622 (1999)

[7] M.I. Mikhailov and V.D. Shafranov, Nucl. Fusion 30, 413 (1990) 


\section{External Distribution}

Plasma Research Laboratory, Australian National University, Australia

Professor I.R. J ones, Flinders University, Australia

Professor J oão Canalle, Instituto de Fisica DEQ/IF - UERJ , Brazil

Mr. Gerson O. Ludwig, Instituto Nacional de Pesquisas, Brazil

Dr. P.H. Sakanaka, Instituto Fisica, Brazil

The Librarian, Culham Laboratory, England

Library, R61, Rutherford Appleton Laboratory, England

Mrs. S.A. Hutchinson, JET Library, England

Professor M.N. Bussac, Ecole Polytechnique, France

Librarian, Max-Planck-Institut für Plasmaphysik, Germany

J olan Moldvai, Reports Library, MTA KFKI-ATKI, Hungary

Dr. P. Kaw, Institute for Plasma Research, India

Ms. P.J . Pathak, Librarian, Insitute for Plasma Research, India

Ms. Clelia De Palo, Associazione EURATOM-ENEA, I taly

Dr. G. Grosso, Instituto di Fisica del Plasma, Italy

Librarian, Naka Fusion Research Establishment, J AERI, J apan

Library, Plasma Physics Laboratory, Kyoto University, J apan

Research Information Center, National Institute for Fusion Science, J apan

Dr. O. Mitarai, Kyushu Tokai University, J apan

Library, Academia Sinica, Institute of Plasma Physics, People's Republic of China

Shih-Tung Tsai, Institute of Physics, Chinese Academy of Sciences, People's Republic of China

Dr. S. Mirnov, TRINITI, Troitsk, Russian Federation, Russia

Dr. V.S. Strelkov, Kurchatov Institute, Russian Federation, Russia

Professor Peter Lukac, Katedra Fyziky Plazmy MFF UK, Mlynska dolina F-2, Komenskeho Univerzita, SK-842 15 Bratislava, Slovakia

Dr. G.S. Lee, Korea Basic Science Institute, South Korea

Mr. Dennis Bruggink, Fusion Library, University of Wisconsin, USA

Institute for Plasma Research, University of Maryland, USA

Librarian, Fusion Energy Division, Oak Ridge National Laboratory, USA

Librarian, Institute of Fusion Studies, University of Texas, USA

Librarian, Magnetic Fusion Program, Lawrence Livermore National Laboratory, USA

Library, General Atomics, USA

Plasma Physics Group, Fusion Energy Research Program, University of California at San Diego, USA

Plasma Physics Library, Columbia University, USA

Alkesh Punjabi, Center for Fusion Research and Training, Hampton University, USA

Dr. W.M. Stacey, Fusion Research Center, Georgia Institute of Technology, USA

Dr. J ohn Willis, U.S. Department of Energy, Office of Fusion Energy Sciences, USA

Mr. Paul H. Wright, Indianapolis, Indiana, USA 
The Princeton Plasma Physics Laboratory is operated by Princeton University under contract with the U.S. Department of Energy.

\author{
Information Services \\ Princeton Plasma Physics Laboratory \\ P.O. Box 451 \\ Princeton, NJ 08543
}

Phone: 609-243-2750

Fax: 609-243-2751

e-mail: pppl_info@pppl.gov

Internet Address: http://www.pppl.gov 